\title{
Implementation Strategy of College English Online Blended Teaching Model
}

\author{
He Yuying \\ Jincheng College of Sichuan university, Chengdu, Sichuan610000, China \\ 1469486461@qq.com
}

\begin{abstract}
In 2020, the new coronavirus is pushing online teaching to every learner, and online teaching will really come into our lives. The hybrid teaching mode, which combines students' online micro-class autonomous learning with offline teachers' face-to-face classroom teaching, has been implemented in various colleges and universities in full swing recently. The teaching reform mode of "flipped classroom", which mainly takes the form of "micro-class" and "MOOC", has brought significant positive influence to the promotion of English teaching effect. For example, the interaction between teachers and students has been strengthened due to the online and offline cooperative teaching activities. Meanwhile, students' learning efficiency in listening, speaking, reading and writing has been greatly improved. Furthermore, the kind of mode has made a difference in changing students' passive learning state, enabling students to become active learners of English and enhancing their competitiveness through language learning. By analyzing the challenges appeared in college English teaching, this paper aims to explore the strategies of designing and implementing online blended teaching, so as to shed some light on the development of online teaching in the future.
\end{abstract}

Key words: college English, online blended teaching, strategy

\section{INTRODUXTION}

In 2020, a new coronavirus rags in China and the world, surprises people, and plunges them into anxiety and panic. At the same time, in the field of education and teaching, offline face-to-face teaching has fallen into a helpless state, and online education based on the Internet is imperative, ushering in unprecedented opportunities for development, just like college English education and teaching. After the epidemic, college English teaching is bound to move towards the new normal of the widespread use of the Internet. It has become a challenge and opportunity for foreign language teachers in colleges and universities to make use of the resources of network platform for effective teaching. It is also an opportunity for learners to cultivate their independent learning ability.

\section{CHALLENGES OF COLLEGE ENGLISH TEACHING BASED ON INTERNET}

\subsection{The traditional teaching mode contradicts the demand for talents in the new era}

Under the impact of the Internet information age, the traditional teaching mode has obvious disadvantages including the single teaching content as well as dull teaching methods, which continuously kills the enthusiasm of students and greatly reduces the effect of English learning. Many teachers have used multimedia equipment to assist their teaching, but only to explain PPT contents, so their teaching only stays in the level of sorting out the knowledge of the textbook and the transference of book knowledge. What's worse, teaching content still stays in the level of word memory and grammar explanation. Although this kind of teaching also USES the Internet, it is not called "Internet + " teaching and at best a different way of content display. However, under the current era of higher and higher demands for talent quality, this exam-oriented teaching model has not kept up with the pace. At this time, the reform of hybrid teaching mode under the Internet information platform arises at the historic moment, which can alleviate this problem in time. In this way, college English education can make better and better use of the existing resources of teachers to truly teach students according to their aptitude.

\subsection{The single evaluation method is inconsistent with the practical application ability}

At present, various colleges and universities are still in the examination of English mainly in the closed book test, and the test type is still focused on listening, writing, reading, grammar and translation of "standardized" questions. Although the closed-book exam involves the students' subjective application ability, it cannot comprehensively assess the students' language expression ability. In order to cope with the exam, many students choose to memorize by 
rote, which eventually lacks the practice of actual language expression ability. Moreover, this kind of examination method, taking the student's examination result as the measurement standard, is relatively single, failing to check the student's study progress, and also ignoring the student's independent study ability.

In addition, considering the level of students, although many colleges and universities have conducted a simple class placement test for a large number of students, even in the same level, there is still a big difference between students' ability and degree. More importantly, students have different learning priorities, so teachers cannot meet all students' learning goals with the same set of teaching materials. If different teaching materials and different teaching methods are used, the number of students is large and the teaching staff is not enough [2]. By contrary, the hybrid teaching mode with "micro-course" and "MOOC" as the main forms of resource expression can well solve the above problems. Based on the reason above, this paper explores the construction strategies of hybrid teaching mode in the new situation in order to help college English teaching.

\section{THE CONSTRUCTION STRATEGY OF COLLEGE ENGLISH ONLINE BLENDED TEACHING MODE UNDER THE NEW SITUATION}

Blended teaching refers to the effective and efficient combination of the advantages of previous face-to-face learning and E-learning (digital or networked) learning to achieve the best learning effect [1]. Internet-based online classes are different from traditional face-to-face teaching. Learners have different resources. In traditional classroom teaching, students have textbooks, workbooks, teacher's notes and other paper materials in hand, which are printed clearly at a glance. It's easier and more effective for students to follow the teacher's instructions and deal with some class activities, while in online classes, due to various reasons, learners are often unable to start their lessons due to the lack of printed materials or the huge amount of network resources. At this time, teachers are required to be the screeners, designers, organizers and evaluators of online resources to effectively assist learners to make use of online resources and implement effective learning practices.

Online teaching activities are carried out through the combination of students' micro-class autonomous learning and teachers' face-to-face classroom teaching offline. The teaching mode of flipped teaching, aiming at strengthening the interaction and building an effective cooperative relationship between teachers and students, has been beneficial to students' English ability in listening, speaking, reading and writing, actually improving their learning efficiency. It has changed the state of students' passive learning, making them become active learners as well as upgrading their competitiveness through language learning. The following strategies should be paid attention to the construction of hybrid teaching mode:

\subsection{Change the concept and give full play to the advantages of online classes}

In order to carry out online teaching effectively, the characteristics of online classes need to be clarified. Online classroom teaching process is the teachers, as selector of online resources, designers, organizers and evaluators, design diversified online teaching activities based on digital resources related to the teaching content, effectively assist learners to use online resources and give full play to the record of online resources, feedback and evaluation function. That is, through learners' learning activities, they can experience, acquire knowledge and finally get achievement via assessment. Therefore, teachers should change their ideas in time and adopt the teaching organization, teaching content and interactive methods suitable for online classes.

\subsection{Focus on resource learning and design teaching reasonably}

Designing effective teaching activities includes:

\subsubsection{Optimize teaching and identify online resources.}

Relying on the abundant English learning resources on the network platform, such as video teaching materials, text teaching materials and audio recording teaching materials, students can understand the English culture well through multiple channels, experience the language expression habits and interpersonal communication habits from English-speaking countries, and actively cultivate their listening, speaking and expression skills with the help of these resources, thus meeting their different learning needs. However, in the process of learning resources selection, it is advisable for teachers to choose the network resources related to English teaching content rather than a blind choice. The principles selected by the teachers can be applied: ready-to-use online systems, lectures or electronic chapters in textbooks, etc., as well as some foreign language reading and listening materials developed by the teachers themselves. Either way, grasp the ultimate goal: to enable learners to absorb useful information and use it to enhance their ability [3].

\subsubsection{Make the teaching objectives clear.}

The basic principle of setting teaching objectives is based on online resources. When teachers select materials, input and autonomous content based on the goal of promoting online learning can be taken into account. For example, teachers can assign some listening and reading materials to 
cultivate learners' abilities in vocabulary acquisition, discourse cognition and cultural literacy, boosting students' autonomous learning ability.

\subsubsection{Grasp the basic principles: adhere to the student-centered, teacher-led principle [4], make use of strengths and circumvent weaknesses, and give play to the advantages of online teaching.}

Online class is the online transformation of traditional interactive tasks in class. When teaching online, in order to avoid "dictatorial rule" or "cramming method of teaching", teachers can design some small exercises, do more small tasks, and set small goals, such as one-sentence questions and quizzes, to achieve the combination of speaking and practicing. At the same time, the accurate analysis of learning situation can be carried out to achieve the knowledge guidance, cognitive help, emotional motivation, or exposure to the platform progress bar (the whole class feedback and praise, individual warning and encouragement) to monitor students' learning progress and feedback students' learning quality. For instance, in order to detect students' learning effect at the vocabulary level, online real-time test, real-time key explanation and real-time feedback recording can be adopted. Small interactive communication can be used on the line: personal activities such as a question and answer, answer thumb up, mobile phone text input, students-initiated questions or group activities including the big class QQ layout, group QQ discussion, group QQ sharing, class vote points like, finally the teacher gives reference answers.

\subsection{Strengthen the management of online and offline teaching process}

The management of online classroom should be strengthened from three aspects: target level, curriculum level and classroom level. In the aspect of goal management, it mainly clarifies the goal of online learning and emphasizes effective learning. At the curriculum level, teachers can release online learning plans in advance on the online learning platform to clarify the progress, homework and assessment requirements, so that learners have a further understanding of the course, in order to set goals and make a good learning plan. At the classroom level, teachers make and release online resource learning task list in advance, track and analyze students' online learning behavior, and study and choose the guidance points, so as to give timely feedback.

Nevertheless, the specific teaching process covers pre-class, in-class and after-class. The teaching arrangement is based on online learning, driven by dynamic data of online learning, and by means of online synchronization and targeted problem solving, so as to timely adjust the offline classroom teaching plan, organize class discussions and group reports, and make students truly integrate into the classroom. The specific teaching design is as follows:

\subsubsection{Online "teaching" and "learning" before class}

The goal of this stage is memory and understanding. Before class, teachers should analyze students' online learning behavior, determine the online classroom teaching objectives, design various test questions derived from the output-oriented method, select typical sample analysis materials and make PPT, task list and other materials. Under the guidance of teachers, students complete independent learning and carry out group cooperation.

\subsubsection{Offline "teaching" and "learning" in class}

The teaching objective of this stage is application and analysis. Based on the online learning content, teachers can clarify questions and solve problems, and then expand, analyze and summarize the content conducting effective teacher-student interaction and student-student interaction guided by questions and tasks. Students will present their learning results in groups to promote their thinking ability in application, analysis, evaluation and creation, so as to maximize the teaching effect. In this stage, teachers should carry out the teaching process in terms of plan, organize students' activities and deal with emergencies at the same time.

\subsubsection{Online "teaching" and "learning" after class}

The teaching objective of this stage is evaluation and output. The teacher urges students to reflect, apply and internalize the content of pre-class learning and in-class refining. Students complete online learning tasks through exploratory projects, peer review, online assessment and other diversified evaluation methods, so as to improve their problem-solving ability and creativity. Online classroom environment is a new opportunity for in-depth understanding, application and reflection of teaching theory. After class, teachers should timely reflect their online organization form and combine theory with practice to achieve the goal of cyclic improvement.

In short, the three stages of pre-class, in-class and after-class gradually increase the level of challenge with the cognitive process. Namely, teachers, as guide, clarify task requirements and provide knowledge and language support. Students, as the main body, gradually complete the in-depth learning of knowledge. It is worth noting that when implementing class organization and management as well as establishing online class management mechanism, teachers should trust students and rely on their basic principles to give full play to the role of student teaching 
assistants. Thus, for the sake of evaluating well, the big class can be classified into small groups, respectively setting up QQ, WeChat or other online communication groups and using professional teaching platform to record the teaching process and learning performance. The essence of management is service. Through the combination of individual efforts such as studying students' educational background, studying their learning situations, serving students' real learning needs, and overall and individual guidance, teachers make students feel that online learning will be more effective.

\subsection{Optimize the teaching evaluation system}

Scientific, reasonable and effective evaluation system can not only stimulate students' learning drive, but also make objective and fair evaluation on students' learning process and teachers' teaching process, so as to promote the teaching quality. For flipped classroom under the guidance of hybrid teaching mode, to optimize the teaching evaluation system, it is necessary to start from the three aspects of integrity, objectivity and diversification: first, the integrity of the evaluation system. That is, in the teaching evaluation, the teaching activities of each aspect of the multi-angle, comprehensive evaluation, cannot be generalized. For example, for the evaluation of students, not only should the students' academic performance be evaluated, but also the students' preview before class, the interactive communication and exhibition in class and the completion of homework after class should be evaluated comprehensively. Second, the evaluation system should be concerned about objectivity. The evaluation results should conform to the objective reality, and should not be mixed with personal feelings and subjective assumptions. For example, the objective assessment of students should not only combine with the teachers' objective evaluation results, but also with the students' self-assessment and the students' internal and external objective assessment. Third, the diversification of evaluation system should be seen during the process of assessment. One of the purposes of the reform of hybrid teaching mode is to change the situation of single means of teaching evaluation in traditional teaching in the past. Therefore, it is an effective means of assessing learners' learning effect to add learning process records in the form of homework, test, discussion, speech and communication.

\section{CONCLUSION}

In hybrid teaching mode, we must first define the purpose of the hybrid, and then effectively use or actively construct online resources suitable for our school personnel training goal. By using hybrid teaching mode to carry out effective means, the respective advantage of online teaching and face-to-face teaching can be maximized to carry out team construction, providing basic guarantee for effective teaching. No matter online or offline, the learning cognitive law, knowledge inheritance value, interpersonal relationship between teachers and students, and the purpose of evaluation and feedback remain unchanged. What changes is only the input mode of information, that is, the content presentation mode, knowledge teaching mode, teacher-student interaction mode and evaluation and feedback mode. No matter which teaching mode, it should serve the actual needs of English teaching in various colleges and universities. The blended teaching mode should adapt to the requirements of the times and serve the English teaching effectively by promoting the English teaching level in colleges and universities.

\section{REFERENCES}

[1] He Kekang. (2005). The New Development of Educational Technology Theory from Blending Learning. Journal of National Academy of Education Administration, 9: 37-48.

[2] Yu Hongtao. (2017). A Case Study on the Effect Evaluation of Mixed Teaching Reform in Institutions of Higher Learning -- a Case Study of Inner Mongolia University for Nationalities. China Electrochemical Education, 370: 129-133.

[3] Li Ying. (2016) Research on the Mixed Teaching Model of College English Based on Flipped Classroom. Journal of Liaoning University of Technology (social science edition), 18: 115-118.

[4] Zhang Huan. (2014) Research on Mixed Teaching Model of College English in Network Environment. Youth and Society, 31: 30-32. 